\title{
¿Qué hacemos con tanto muerto junto? Tratar la muerte violenta y masiva en el Medio Atrato
}

\author{
What do We do with All the Dead? \\ Understanding Mass Killings in the Medio Atrato
}

Diana Camila Orjuela Villanueva*

DOI: $10.22380 / 2539472 X .648$

\begin{abstract}
RESUMEN
La masacre de Bojayá ocurrió en el 2002 en la cuenca media del río Atrato (Pacífico colombiano) y produjo la muerte masiva, violenta y privada de ritual de aproximadamente 98 personas. Por más de 18 años los familiares y la comunidad atrateña han buscado que sus seres queridos fallecidos a causa de este crimen de lesa humanidad habiten la vida de los vivos como ancestros y ángeles protectores. Para ello realizaron, reinventaron y crearon prácticas rituales que han supuesto la expansión temporal de su ejecución, la agencia del saber mortuorio de los expertos locales y el diálogo e interpelación con prácticas rituales foráneas. Este artículo presenta una etnografía sobre el entretejido ritual agenciado para que esos difuntos Ileguen a puerto seguro y puedan descansar en paz.
\end{abstract}

Palabras claves: masacre de Bojayá, mala muerte, guerra, rito.

\begin{abstract}
The Bojayá massacre that occurred in 2002 in the middle basin of the Atrato River (Colombian Pacific) resulted in the massive, violent, and non ritualizaed death of approximately 98 people. For more than 18 years, their relatives and the Atrato community have sought that their loved ones, murdered in this crime against humanity, inhabit the world of the living as ancestors and protective angels. In doing so, they have reinvented and created ritual practices that involve the temporal expansion of their execution, the mortuary knowledge of local experts and dialogue and interpellation with foreign ritual practices. This article presents an ethnography of the interwoven ritual practices for the deceased to arrive at a safe harbor and rest in peace.
\end{abstract}

Keywords: Bojayá massacre, mala muerte, war, ritual practice.

camilaorjuelavillanueva@gmail.com / https://orcid.org//0000-0001-7975-5040 


\section{Introducción}

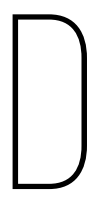

esde una ventana enverdecida por la maleza, con sus contornos de pared derruidos y ajados, escucho lejanas las voces de una multitud. Veo personas cuyos rostros, borrosos e imposibles de reconocer, siento familiares. Me percibo inmóvil. Atestiguo sonrisas espontáneas. Cuerpos diversos caminan hacia algún lugar común. Sus pasos son lentos y están en contacto con las hojas secas que van encontrando en su camino. Observo y callo. Abruptamente, la multitud desaparece; en su lugar un coro de lamentos; escucho gritos, susurros sobre mi espalda, hay llanto... ahogos, congojo, súplicas. ¡Despierto! Mi corazón late fuerte, respiro rápido. Pienso en Bojayá, pienso en sus muertos.

Este fragmento corresponde a un sueño que recordé una mañana de agosto del 2016. Cuando desperté, lo escribí ${ }^{2}$ en la libreta donde registré las notas derivadas de las reuniones sobre el proceso de exhumación de las víctimas mortales de un crimen que es conocido y enunciado como la masacre de Bojayá ${ }^{3}$ y que para muchos de los pobladores del Atrato chocoano y antioqueño es recordado como la “toma del 2002”. La exhumación fue resultado de muchos años de movilización de las comunidades del Medio Atrato y de su permanente diálogo, interpelación y concertación en los escenarios transicionales (Castillejo 2015) ${ }^{4}$ colombianos. A partir del 2014, luego de trece años de arduo trabajo, líderes y organizaciones

1 Las personas cuyos nombres y apellidos registro en este artículo brindaron su aprobación y permiso para la publicación, a excepción de un sabedor tradicional que murió recientemente. No excluí su nombre porque desempeñó un papel fundamental en el proceso de acompañamiento a los muertos de la masacre y estuvo al tanto de mi interés etnográfico sobre sus oficios. Asimismo, nombro a algunos difuntos con el interés de contribuir al reconocimiento de sus identidades personales, familiares y comunitarias, lo cual ha sido una premisa para su tratamiento en las prácticas rituales orientadas a su descanso, incluyendo aquellas de tipo forense.

2 La escritura de este sueño dialoga con la consideración realizada por Tobón (2016), quien analiza los sueños como instrumentos etnográficos. Lubin Valencia, bellavisteña, interpretó mi sueño y me dijo lo siguiente: "Solo el hecho de tener la oportunidad de soñar con ellos es una manifestación... es un signo de confianza de ellos hacia usted" (notas de campo, octubre del 2016).

3 Para un análisis de la masacre de Bojayá como crimen culmen de la guerra que se venía agudizando en toda la región del Atrato desde el año 1996, sugiero consultar el informe Bojayá: la guerra sin límites (GMH-CNRR 2010). Para una comprensión de la masacre en el contexto más amplio de violencias históricas y afrodiaspóricas articuladas a experiencias de marginación, racismo y empobrecimiento, véase Vergara (2014).

$4 \quad$ Los escenarios transicionales son espacios sociales caracterizados por "una serie de ensambles de prácticas institucionales, conocimientos expertos y discursos globales que se entrecruzan en un contexto histórico concreto con el objeto de enfrentar graves violaciones a los derechos humanos y otras modalidades de violencia" (Castillejo 2015, 23). 
atrateñas participaron en los diálogos de paz entre el Gobierno y la guerrilla de las Fuerzas Armadas Revolucionarias de Colombia-Ejército del Pueblo (FARCEP). Este proceso posibilitó que la solicitud comunitaria de realizar acciones estatales por el descanso y la despedida final de los difuntos de la masacre fuera escuchada. En el acto en el que las FARC-EP asumieron su responsabilidad en el crimen $^{5}$, la comunidad logró comprometer al Gobierno en la continuidad de un proceso orientado a "llevar a puerto seguro" (Velásquez [1961] 2000) las almas de las mujeres, hombres, niños y niñas que fallecieron en la masacre ejecutada entre el 20 de abril y el 12 de mayo del $2002^{6}$.

Cuando en el 2009 arribé a Bellavista (municipio de Bojayá), presencié la existencia fáctica de un pueblo que dejaba de ser lo que fue. Los bellavisteños se habían trasladado a un nuevo pueblo construido por el Gobierno ${ }^{7}$ y habitaban, un kilómetro río arriba ${ }^{8}$, un paisaje de color grisáceo lejos de la sombra de los árboles, sin la vista bella del río, en casas hechas de cemento ${ }^{9}$ y transgrediendo la norma mortuoria de mantener a los muertos a distancia de los espacios cotidianos. El nuevo pueblo se había edificado en El Fuerte, lugar donde antes se encontraba el cementerio de Bellavista.

Desde el 2009, con mi participación en la construcción del informe de memoria histórica (GMH-CNRR 2010) sobre este hecho violento, pude constatar la manera como vivos y muertos del Atrato le solicitaban al Estado acciones

Este acto se realizó el 6 de diciembre del 2015 en el pueblo viejo de Bellavista, del municipio de Bojayá, y constituyó el primer "acto temprano de reconocimiento de responsabilidad colectiva y petición de perdón de las FARC-EP”. Véase: http://pacifista.co/que-nos-dejen-resollar-asi-sepreparo-bojaya-para-el-perdon-de-las-farc/

El 3 de mayo del 2017, el Cuerpo Técnico de Investigaciones (CTI) de la Fiscalía General de la Nación, por orientación del Gobierno nacional, dio inicio a un segundo proceso de exhumación. El primero ocurrió quince años atrás, cuando los muertos fueron exhumados, parcialmente identificados y luego inhumados en los cementerios de Bellavista, Vigía del Fuerte y Riosucio. El entierro final y los procedimientos forenses y rituales relacionados con él fueron realizados entre el 11 y el 27 de noviembre del 2019. Algunos familiares, sin embargo, están aún a la espera de las acciones forenses que culminen con el entierro o encuentro de sus seres queridos, a quienes nombran ahora como desaparecidos.

7 El nuevo pueblo de Bellavista resultó de la promesa presidencial de Andrés Pastrana expresada el 9 de mayo del 2002. Para el Gobierno fue fundamental dar viabilidad a una obra de infraestructura, con el objetivo de omitir su responsabilidad en la ocurrencia de los hechos violentos, posicionar como único responsable del crimen a las FARC-EP y enviar un mensaje público de recuperación militar del territorio. Para ampliar, véase GMH-CNRR (2010, 179-207).

8 La noción río arriba o río abajo - aprendí de las comunidades atrateñas - tiene que ver con el lugar donde nace (arriba) y donde desemboca (abajo) el río. Cuando utilizan la noción río arriba se refieren entonces a un lugar orientado hacia el nacimiento del río.

9 Quien viaje por el río Atrato constatará, desde su embarcación, que la mayoría de pueblos dibujan una, dos o tres líneas de casas paralelas cuyo material arquitectónico prominente es la madera. 
concretas para revisar el proceso de exhumaciones e inhumaciones que se había llevado a cabo en el 2002. La reubicación de Bellavista en El Fuerte puso en evidencia para la población que los cuerpos de los muertos de la toma yacían en el cementerio, en su gran mayoría sin ninguna señal, lápida o nombre. Así, lo que se constituyó en ese informe como una recomendación sobre justicia y verdad, para las comunidades se experimentaba como una deuda cotidiana con los muertos (Ayala 2011; Velásquez [1961] 2000) que se expresaba, por ejemplo, en la aparición de los difuntos en los sueños de algunos de sus familiares.

En el Atrato los sueños comportan el escenario prioritario de comunicación entre el mundo de los vivos y el de los muertos (Arocha et al. 2008). En los sueños, los muertos pueden relatar letras de oraciones o de alabaos ${ }^{10}$ (Quiceno 2015), transmitir secretos y conocimientos (Millán 2009), exigir ofrendas o promesas, predecir la cura o inevitable muerte de alguien enfermo, presagiar algún evento grato o de tormento, o sencillamente visitar y entablar conversación con el familiar vivo querido (Ayala 2011; Losonczy 2006; Velásquez [1961] 2000).

La mañana del 27 de abril del 2012, en la ciudad de Bogotá, Rosa del Carmen Chaverra compartió por primera vez su experiencia vinculada a la toma del 2002 en un escenario público. Llegada desde el Consejo Comunitario ${ }^{11}$ de Pogue, ubicado en el río Bojayá, Papona — como es conocida por todos—, participó en el foro “Bojayá una década después”. Sentada a su lado percibí sus manos temblorosas y le expresé que si se sentía muy nerviosa podíamos avisar al presentador para que no la llamara como indicaba el guion. Sin embargo, ella me respondió: "No seño, es que mi mamá y mi papá se me presentan en sueños, me dicen que tienen hambre y sed" (notas de campo, abril del 2012). Como lo documentó el antropólogo chocoano Rogerio Velásquez ([1961] 2000), “ánimas que no han llegado a puerto seguro son aquellas que se aparecen en sueños” (164). En el sueño de Papona $^{12}$, su padre y su madre se aparecían y establecían para su hija el imperativo, interpretado luego por un vecino de su pueblo, de rezarles.

En este artículo acojo la noción de alabaos referida por Tobón (2016): “Cantos rituales para velorio y novena de adultos, para celebraciones de Semana Santa y alumbramientos y más recientemente como canto de denuncia social. Su temática se mueve entre textos religiosos y sobre la muerte" (215). Para su comprensión a propósito del dinamismo que esta práctica adquirió en los últimos años en el Atrato, véanse también Pinilla (2017); Quiceno, Ochoa y Villamizar (2017); Riaño y Chaparro (2016).

11 El Consejo Comunitario de Pogue conforma, junto con 123 consejos comunitarios locales más, el Consejo Comunitario Mayor de la Asociación Campesina Integral del Atrato (Cocomacia). Este es la máxima autoridad de administración colectiva de las tierras ancestrales de las comunidades negras de la región del Medio Atrato que fueron adjudicadas por el Instituto Colombiano de la Reforma Agraria (Incora) mediante la Resolución 04566 del 29 de diciembre de 1997. 
Ahora bien, quien arribe hoy a Bellavista encontrará una versión del pueblo distinta a la que yo encontré en el 2009. Los jardines y las azoteas ${ }^{13}$ en el interior y exterior de las casas han hecho del color grisáceo, antes imperante, apenas uno de los colores que se mezclan con las flores de los pichindecillos, las hojas de la lluvia de oro, los bejucos del carácter de hombre, la albahaca, el paico, la menta, la yerbabuena y el toronjil. El cementerio dejó de ser un espacio desolado y las cruces de madera que identificaron a los muertos con números de actas de defunción, tras la intervención forense realizada en el 2002, fueron reemplazadas paulatinamente por las palmas de cristo $^{14}$. En el cementerio ya no encontrará la fosa que hizo que los muertos estuvieran varios años perdidos ${ }^{15}$, sino los espacios en los que se dispusieron los cuerpos de los difuntos tras los procesos de exhumación, individualización, entrega y entierro que se llevaron a cabo entre el 3 de mayo del 2017 y el 27 de noviembre del 2019.

Con mi participación en las conmemoraciones y prácticas mortuorias con los muertos de la toma del 2002 he podido constatar la persistente e inquebrantable relación entre la vida y la muerte que caracteriza las cosmovisiones y espiritualidades de las comunidades negras e indígenas del Medio Atrato (Quiceno 2015). Por ello, con este artículo sugiero que el crimen de guerra y lesa humanidad ocurrido en el 2002 en el Medio Atrato (GMH-CNRR 2010) no suspendió ni quebrantó las relaciones de los vivos con sus muertos; por el contrario, produjo la activación de un conjunto de prácticas rituales (Arocha et al. 2008; Ayala 2011; Losonczy 2006; Quiceno 2015; Velásquez [1961] 2000), las cuales persisten hasta la actualidad y son sostenidas por un conjunto de relaciones entre vivos y muertos (Escobar 2015) que se han entretejido y transformado dinámicamente a propósito de la muerte violenta y del posterior tratamiento comunitario e institucional (Rousseau 2015) dado a los difuntos para lograr el cierre de un ciclo colectivo ritual (Losonczy 2006).

13 Las azoteas o zoteas materializan una forma de siembra particular de las comunidades del Pacífico. Son construidas sobre canoas o cajones de madera, en especial por las mujeres, y albergan principalmente plantas medicinales, aromáticas o de sazón diaria para la gastronomía propia.

14 La palma de cristo es una planta ornamental que puede alcanzar una altura de casi dos metros. Se identifica por las hojas de color rojo que se encumbran en su copa y son señal de la existencia de los cementerios que se riegan a lo largo de las riberas del río Atrato y de sus afluentes. Ayala (2011) señala adicionalmente que "esta planta por su nombre, la forma y el color, es sagrada y bendita para los difuntos porque los ayuda a descansar en paz" (108).

15 La noción perdidos es la que los familiares y la gente de la comunidad utilizó para referirse al estado en que se encontraban sus muertos tras la intervención forense estatal llevada a cabo en el 2002. Luego de la realización de las acciones forenses más recientes (ejecutadas desde mayo del 2017), los muertos no encontrados han empezado a denominarse desaparecidos. 
Para desarrollar las ideas expuestas, este artículo se estructura de la siguiente manera: en primer lugar, presento las prácticas rituales realizadas por la comunidad bojayaseña tras la masacre, orientadas a establecer, mantener y proteger la ontología relaciona ${ }^{16}$ entre vivos y muertos afroatrateños, a la vez que su ejecución sobre la base de prescripciones mortuorias. En segundo lugar, documento prácticas rituales que dan cuenta de la innovación, creatividad y dinamismo que caracterizan la expansión temporal del ciclo ritual colectivo de acompañamiento a los muertos tras la muerte masiva, abrupta y violenta. La tercera parte registra situaciones etnográficas en las que las prácticas rituales de familiares y la comunidad dialogan y entran en contradicción con las relaciones que tejen actores externos con los muertos de la masacre, estas últimas dinamizadas por el tratamiento de la mala y masiva muerte en un contexto de justicia transicional y de acuerdos de paz.

\section{Al muerto no se le corta el alabao}

Día a día, desde 1968, Domingo Chalá se encarga de registrar los niveles de lluvia en Bellavista. También compone y canta vallenatos que son reconocidos e interpretados en toda la cuenca media del río Atrato. Domingacho, como cariñosamente le dicen los más jóvenes, se encarga además de las rotura ${ }^{17}$ y sepulturas de quienes, una vez muertos, se convierten en los ancestros o ángeles que acompañan y protegen la vida de los vivos (Arocha et al. 2008; Ayala 2011; Losonczy 2006; Millán 2009; Quiceno 2015; Ríos 2015; Velásquez [1961] 2000).

El 2 de mayo del 2002, tras el estallido de un cilindro de gas lleno de metralla en la iglesia San Pablo Apóstol de Bellavista, no se pudieron realizar los

16 Para Arturo Escobar (2015), la ontología relacional caracteriza a muchos pueblos étnico-territoriales que, como los del Pacífico colombiano, tienen concepciones del mundo no dualistas, al considerar que los "humanos y no-humanos (lo orgánico, lo no-orgánico y lo sobrenatural o espiritual) forman parte integral” (98) de múltiples mundos en sus múltiples interrelaciones.

Así se llama al lugar de albergue del cuerpo del muerto. Esta noción es referida por la etnografía de Velásquez ([1961] 2000). Se podrían considerar como sinónimos las palabras hoyo y sepultura — utilizadas también en Bojayá-; la palabra tumba —empleada en contextos urbanos como Quibdó-, o la palabra fosa — noción usada o referida a propósito de la llegada de funerarias a Chocó (Arocha et al. 2008; Ayala 2011) y, años más tarde, de las prácticas forenses vinculadas a "escenarios transicionales"-. 
cantos y rezos requeridos por cada muerto ${ }^{18}$ porque el miedo y la continuidad de los combates entre la guerrilla y los paramilitares no lo permitieron. Domingo, acompañado por un grupo de hombres ${ }^{19}$, emprendió la tarea de recoger y disponer en bolsas negras los cuerpos de amigos, familiares, compadres y comadres, para luego trasladarlos ${ }^{20}$ a un hoyo cavado en las orillas del río Bojayá. Entonados con aguardiente y en medio de lo que Domingo me relató como "una pura carnicería”, el grupo de hombres llevó a cabo este trabajo bajo una presión adicional de la guerrilla: "si no recogíamos todo ese personal, ellos quemaban todos esos cuerpos... eso no lo podía permitir, porque ya era muy pesado para mí que los quemaran”. Domingo recuerda haberles dicho a quienes yacían ensangrentados y rotos: "denme el valor de recogerlos” (notas de campo, 2014).

En los mismos días en que se realizaba esta labor, don Enrique, embarcado desde el río Bojayá, llegó a Bellavista y recogió los cuerpos de su suegra, Rufina Hurtado Cuesta, y de su hijo Ilson Rentería para luego trasladarlos hasta su pueblo, la comunidad de Pogue. La Negra, líder local, coordinadora, compositora y cantadora del grupo de alabaos de este consejo local comunitario, me contó que el día que don Enrique volvió no sabían muy claramente qué hacer con “dos cadáveres juntos”. Sin embargo, dispusieron los cuerpos en ataúdes construidos por hombres de la comunidad y luego los ubicaron en la tumba ${ }^{21}$ construida en una de las casas principales del pueblo. Esa noche se les hizo velorio, se les acompañó, lloró y se les "rez[aron] sus cinco rosarios, el primero a las ocho, el segundo a las diez, el tercero a las doce, el cuarto a las dos y el último a las cuatro"; también “hubo sus cantos” y “se repartió solo café”. Horas más tarde, en la “rotura se

18 Digo por cada muerto porque, cuando la muerte acontece en el Medio Atrato, la realización de las prácticas orientadas a su acompañamiento difiere según la clasificación que se haga del muerto como a) querubín, b) erubín, c) ángel patón o d) adulto (Mosquera y Orjuela 2017).

Cuando le pregunté a Domingo quiénes eran esos otros hombres que (de Bellavista y Vigía del Fuerte) lo acompañaban, me respondió: "Yo estaba muy confundido y lleno de dolor... había perros, una marrana y gallinazos...".

Este traslado, me contó Domingo, fue claramente restringido por la presencia masiva de la guerrilla que determinó que solo podrían ser recogidos los muertos que estaban en la iglesia, en la casa de las misioneras hermanas agustinas y en el trayecto entre dichos espacios y la ribera del río. "El otro personal", guerrilleros y paramilitares, no fue recogido.

21 En el ritual mortuorio afroatrateño, la tumba se construye en la sala de la casa de un familiar del muerto y se dispone como el espacio en el que se le harán todos los procedimientos previos necesarios para su entierro (Arocha et al. 2008; Ayala 2011; Velásquez [1961] 2000). Allí se le velará y acompañará -idealmente-durante ocho noches más. Saulo Mosquera, líder, rezandero y cantador del Consejo Comunitario de Pogue, me precisó: "para el velorio y hasta la penúltima noche ponemos en la pared de la sala una sábana blanca, una mariposa negra [cuya forma logran con el pliegue que le hacen a un trapo de dicho color]; para la última [noche de novena] hacemos arcos con madera traída del monte... la tumba se mejora". 
enterraron juntos suegra e hijo de Enrique”. La novena, "con todo el miedo que teníamos, no se hizo"22 (notas de campo, 2018).

Durante mucho tiempo asumí que la relación entre vivos y muertos había sido profundamente quebrantada por la masacre. Sin embargo, documentar estas prácticas me permitió reconocer que la relación se sostuvo desde el mismo momento en que aconteció la muerte masiva y que su configuración se manifestó -y ha venido manifestándose- en íntima concordancia, diálogo y a la vez reinvención con las prescripciones que caracterizan la ritualidad mortuoria afroatrateña.

A partir de su trabajo realizado durante la década de 1960 en el Bajo y Alto Chocó, Rogerio Velásquez ([1961] 2000) documentó que la ritualidad de las comunidades negras se componía de varios preceptos ${ }^{23}$ : un tiempo de presagios, en el que la muerte se hace presente a través de signos que la anuncian; un tiempo de la agonía y la muerte, en el que familiares y amigos acompañan y esperan con rezos y llantos el paso a mejor vida del moribundo; el tiempo de tratar y preparar al muerto, en el que se baña, se purifica, se viste y se le dispone para dar inicio al ciclo ritual colectivo de acompañamiento; el tiempo de creación del altar y la tumba, tiempo para encender cinco velas, colgar una sábana blanca y sacar las imágenes de los santos; el tiempo de una noche de velación, la primera de nueve, para compartir con la parentela venida de cerca y lejos y para acompañar el dolor, el llanto y el lamento con cantos de alabaos, rezos, chistes, cuentos, comida y aguardiente. Luego está el tiempo para abrir el hueco, disponer al muerto en el ataúd, pasearlo para la despedida de sus lugares más queridos y sepultarlo; después, en el caso de los adultos, transcurren nueve noches de rezos de rosario y oraciones, que llevan a la última noche en la que se levantará la tumba y el alma del difunto se irá del mundo de los vivos. Para quienes mueren siendo niños no hay novena, será suficiente su velorio con cantos de romances y no de alabaos (132-171). Este conjunto de elementos constitutivos de los rituales mortuorios ha

22 Otros dos entierros se realizaron en medio del miedo que producía la continuidad de los combates. El del bebé Moisés Osorno Palacios, a quien su padre, después de dos intentos por lograr cruzar el Atrato desde Vigía hasta Bellavista, lo recogió, lo trasladó a Vigía y lo enterró. Así mismo pasó con el cuerpo de Ubertina Martínez, asesinada en Napipí y enterrada por sus familiares en el cementerio de Vigía del Fuerte.

Hago uso de las palabras precepto, prescripción o mandato mortuorio para dar cuenta de las responsabilidades, obligaciones y compromisos de los dolientes con sus muertos, los cuales se materializan en procedimientos, principios morales o pasos que son necesarios para que el ritual mortuorio se haga bien y logre su finalidad reparativa de balance. Sustento esto en las etnografías existentes sobre estos rituales, a la vez que en la noción local de espitirualidad antigua que se conecta con la noción de ancestralidad y de los saberes, en este caso, espirituales, que se transmiten de generación en generación para lograr que tanto los vivos como los muertos sostengan su relación ontológica. 
sido revisado y ratificado por la exposición e investigación "Velorios y santos vivos” (Arocha et al. 2008) y por el trabajo de Gilma Ayala (2011). Estas fuentes registran, además, otro precepto ${ }^{24}$ : el cabo de año o aniversario ${ }^{25}$.

Ahora bien, dichas prescripciones caracterizan la ocurrencia de lo que los estudios han documentado como buena muerte o buen morir, a saber: aquella que "ocurre en la cama, con largos días de padecimientos, al lado de la familia y con alivios religiosos” (Velásquez [1961] 2000, 141), que “le permitirá [al difunto] “irse bien”" (Losonczy 2006, 31). En oposición ${ }^{26}$, se documenta la mala muerte o mal morir, que es cuando la muerte "ocurre súbitamente, sin que los sentidos tengan tiempo de hacer dejación de lo terreno”, y puede ser considerada como castigo de las almas (Velásquez [1961] 2000, 141). La mala muerte deja las almas errantes y “ocurre [...] sin los rituales funerarios” (Losonczy 2006, 132).

A propósito de lo anterior, con la agudización de la violencia en el Atrato, Millán (2009), Ríos (2015) y Quiceno (2015) documentan la muerte recurrente, masiva y colectiva acontecida en la masacre del 2002 como mala muerte. Millán (2009, 44 y 94) aduce que esta mala muerte aconteció en la iglesia y en la mañana, a diferencia de la documentada por Velásquez ([1961] 2000) y caracterizada por Losonczy (2006) como aquella que "sucede en la selva, espacio de lo bravo, lo salvaje y lo divino” (132).

En este punto es importante una consideración. La bibliografía revisada es amplia al referirse a la forma que adquieren las prescripciones mortuorias vinculadas a la buena muerte, lo cual no pasa en igual medida con su dimensión opuesta. Las referencias existentes, sin embargo, detallan variaciones en los modos en que se trataba el cuerpo. Por ejemplo, "si el fallecimiento lo ha originado un homicida que ha huido”, el cuerpo se ha de disponer boca abajo (Velásquez [1961] 2000, 139). Dichas prácticas pueden considerarse como variaciones que dialogan con un mandato mayor, que parece actuar como imperativo en el acontecer de la muerte, ya sea esta buena o mala. Ese precepto consiste en lograr el

24 Serrano $(1998,189)$, quien también documentó este tipo de prácticas, señaló que existe un paso previo al aniversario que es el cumplemés. Sin embargo, no encontré, ni en campo ni en la literatura revisada, referencias a este momento. ritmo temporal atrateño, como señala Ayala (2011), no es del todo claro. Pero es recurrente identificar su práctica en los anuncios de la prensa escrita, en las cuñas radiales o en carteles pegados en las paredes de las calles, iglesias o del hogar del difunto.

La ocurrencia de la muerte en las comunidades negras del Chocó, señala Losonczy (2006), requiere de una perspectiva que la comprenda en el encuentro de "tres sistemas simbólicos: el de los orígenes africanos [...]; el del catolicismo hispánico [...]; y el del sistema chamánico de los emberá y waunaná" (43). Bajo este marco de comprensión, buena muerte y mala muerte, dice la autora, harían parte de los ejes del pensamiento clasificatorio de las comunidades negras, caracterizados fundamentalmente por bipolaridades y oposiciones espaciales (125). 
descanso de las almas, la protección y la tranquilidad de los vivos y la conversión de los muertos en ancestros y ángeles (Arocha et al. 2008; Quiceno 2015).

Así, el conjunto de prácticas mortuorias realizadas los días posteriores a la toma del 2002 manifiesta un trabajo que sostiene y dinamiza la relación de los vivos con sus muertos en medio de la experiencia de sobrevivir y de proteger la vida pese al miedo, los combates y las amenazas. Proteger a los muertos de ser quemados, conversar con ellos, pedirles permiso para organizarlos, cargarlos, embarcarlos y llevarlos a un lugar de disposición transitorio, o buscarlos para rezarles, cantarles, velarlos y enterrarlos dan cuenta de la diversificación de las prácticas mortuorias, pese a lo masivo de esta mala muerte y de sus implicaciones para la gente. Pone de presente, además, que la mala muerte desencadena la agencia de quienes realizan las tareas específicas de sepultar (como en el caso de Domingo), velar, rezar, cantar y acompañar (como en el caso de La Negra y del Consejo Comunitario de Pogue), para garantizar que la relación entre vivos y muertos se produzca y se mantenga.

Lo anterior podría tener un correlato en la obra de teatro realizada por un grupo de jóvenes renacientes ${ }^{27}$ en el primer aniversario de la masacre. Una mujer bellavisteña me compartió lo siguiente: "en la obra nosotros hicimos presentes a los difuntos, les enviamos cartas y bailamos con ellos". La obra se llamó Los muertos hablan: "la gente piensa que ellos [los muertos] no hablan ${ }^{28}$ o que no están. Y ellos están, ellos viven ahí, con uno, con su pueblo” (notas de campo, 2013).

Cuando se ha hecho referencia a la mala muerte producida por la masacre, Millán (2009), Ríos (2015) y Quiceno (2015) señalan que esta deja en un "no lugar a los difuntos”. Esto fundamentalmente lo atribuyen a la ausencia de los rituales que permiten el acompañamiento colectivo de los vivos a sus muertos. Sin embargo, la conversación registrada invita a comprender que muertos y vivos configuran una ontología relacional en la que bellavisteños, bojayaseños y atrateños reconocen a quien muere como un acompañante en la experiencia histórica de los pueblos afros y negros. En razón de lo anterior, podemos comprender que un adulto que muere sea reconocido como ancestro, dado que su papel de autoridad como padre, madre, abuelo o abuela se extiende y articula a la experiencia que

27 Uso, en los términos de Almario (2001), el etnónimo coloquial renacientes, utilizado por bojayaseños y atrateños para dar cuenta de sí mismos en relación con: a) la descendencia de sus ancestros esclavizados; b) la nominación que reciben los niños, niñas y jóvenes del Atrato; c) la experiencia de sobrevivir, y por tanto renacer, respecto a hechos de violencia histórica reciente como la masacre de Bojayá. no hablan, texto sobre la masacre que escribió el periodista español Paco Gómez Nadal (2012). 
reivindica la descendencia de quienes murieron en la trata esclavista ${ }^{29}$ (Arocha et al. 2008; Ayala 2011; Serrano 1998). Por su parte, quienes mueren siendo niños adquieren la identidad de ángeles protectores, pues la muerte los encuentra libres de pecado ${ }^{30}$ y les permite una entrada directa al cielo ${ }^{31}$. Reiterar, por tanto, que los muertos hablan y viven entre los vivos y tienen un lugar, independientemente del modo de morir, es interpelar las maneras como comprendemos sus pervivencias a través de la historia.

Ahora bien, mantener la relación con los muertos e insistir en reconocer su existencia en la vida de los vivos implica además resguardar las prácticas que la hacen posible. En la firma del acuerdo de paz entre el Gobierno y la guerrilla de las FARC-EP realizada el 26 de septiembre del 2016 en Cartagena, participó un grupo de diez cantadoras de Pogue. En uno de los ensayos para ensamblar las composiciones que habían llevado, el director artístico del evento les dijo que su “acto musical” contaría con un minuto para su presentación. Leyner, pogueño y líder del Medio Atrato, le dijo: "antes de hablar de música, hablemos de alabao [...] el canto que lleva el alma hacia su tránsito al cielo”, a lo que siguió otra interpelación: "se necesitan no menos de tres minutos". En respuesta, el director les señaló que si no cumplían los tiempos corrían el riego de que las sacaran del aire y cortaran la transmisión televisada. Las pogueñas negaron con su cabeza, cruzaron miradas y una de ellas dijo, de manera enfática, "al muerto no se le corta el alabao". Al día siguiente, estas mujeres cantaron un "alabao por la paz"32, ensamble de composiciones de tres de ellas, que duró más de tres minutos y con ello evitaron un riesgo mayor: cortar el alabao dirigido "a todos los muertos de la violencia en Colombia” (notas de campo, 2016).

De lo anterior podemos afirmar que la relación entre los vivos y los muertos que dejó la masacre de Bojayá se ha construido mediante prácticas rituales que, sustentadas en prescripciones mortuorias de las comunidades negras del

Este elemento sugiere dar continuidad a las reflexiones propuestas por estudios transdisciplinarios (Restrepo 2013) y por las investigaciones sobre las religiones de matriz africana (Castro 2015; Goldman 2016).

30 Esta noción de ángel o angelito, señala Restrepo (2011) en su etnografía sobre la muerte en el Pacífico sur colombiano, se relaciona con "la ausencia de la conciencia y de pecado - entendiendo por ello lo sexual-" (87). Una ampliación sobre nociones como pecado y entendimiento se encuentran en Losonczy (2006, 208-211).

31 A propósito, el siguiente testimonio citado en el "Plan Especial de Salvaguardia de la manifestación gualíes, alabaos y levantamientos de tumba del Medio San Juan": "Para nosotros cuando los niños mueren se convierten en ángeles que van a gozar de los coros celestiales por no tener pecado alguno; por eso decoramos el altar y vestimos al ángel de blanco pureza" (Ministerio de Cultura 2014). 
Medio Atrato y su diversificación, están orientadas, por un lado, a proteger y resguardar el estatuto de sus muertos como ancestros y ángeles, y por otro, a garantizar el descanso de sus almas. También buscan resguardar de intervenciones y actores ajenos la inmanente existencia de los muertos en la vida de los vivos.

\section{¿Qué hacemos con tanto muerto junto?}

Las prácticas rituales y las variaciones de la relación entre muertos y vivos para tratar la mala (y masiva) muerte se caracteriza además por una temporalidad que ha expandido el ciclo ritual colectivo de acompañamiento al muerto, es decir, los aniversarios o cabo de año. Dos situaciones etnográficas ilustran esta idea:

1. En el 2014, cuando las noticias de los diálogos de paz entre el Gobierno y la guerrilla rondaban su fase secreta, las mujeres expertas en la relación cantada con los muertos propusieron realizar para la noche del 2 de mayo un ritual de cuerpo presente en la iglesia donde doce años atrás había acontecido la explosión de una pipeta de gas llena de metralla. Esa noche, en el altar de la iglesia había dispuesta una tumba cuya escenificación reconocí por haberla visto meses atrás en el Encuentro de Alabaos, Gualíes y Levantamiento de Tumbas del Medio San Juan $^{33}$. Con la participación de no más de treinta personas, se dio comienzo a una serie de rezos de rosario larguísimos, que se iban alternando con avemarías, padrenuestros y cantos de alabao. Unos días antes, cuando las cantadoras se reunieron para preparar este ritual, uno de los rezanderos y cantadores dijo: “¿qué hacemos con tanto muerto junto?, ¡nosotros no sabemos cómo cantar y rezar a tanto muerto junto!”. Una cantadora le respondió: “máximo hemos cantado y rezado para dos personas”, “bueno, hagamos un ritual de cuerpo presente”, dijo otra (notas de campo, abril del 2014). Se referían al ritual que se hace para las personas que mueren ahogadas en el río y de quienes no se halla nunca el cuerpo, o de quien muere muy lejos de su lugar de nacimiento y por cuestiones

33 Las Musas de Pogue son el primer grupo de la región del Medio Atrato participante en el encuentro. Son reconocidas por sus composiciones, en melodías de alabao y romance, sobre las violencias históricas y del conflicto armado que ha experimentado la región. El Encuentro de Alabaos, Gualíes y Levantamiento de Tumba del Medio San Juan se realiza desde 1997 con el objetivo de resguardar y visibilizar la manifestación cantada de los rituales mortuorios, intercambiar saberes y hacer un reconocimiento a sus practicantes (Ministerio de Cultura y Fundación Cultura de Andagoya 2014). 
diversas no logra retornar para el ritual de acompañamiento de sus familiares y comunidad de pertenencia ${ }^{34}$.

Figura 1. Tumba que hizo parte del ritual de cuerpo presente en la iglesia San Pablo Apóstol (Bellavista Viejo)

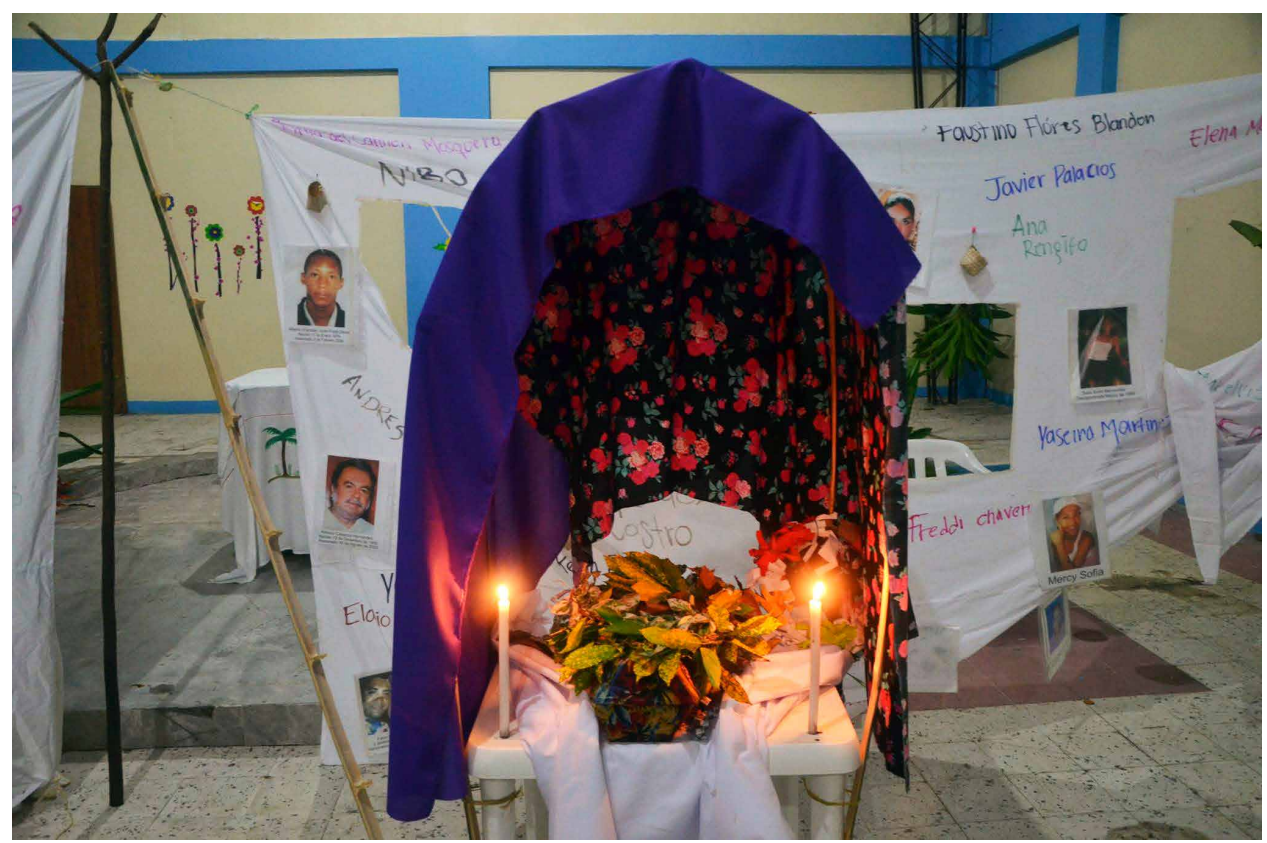

Fuente: fotografía de Camila Orjuela Villanueva, 2 de mayo del 2014.

Esa noche, mientras se realizaba el trabajo ritual, me dirigí a la puerta, pues empecé a sentir que algo en el pecho me apretaba. A las afueras me encontré al grupo de jóvenes acompañantes que jugaban dominó. De dónde salieron el dominó y la mesa, y en qué momento había comenzado el juego, no tuve idea. Sonreí y empecé a observarlos a la vez que recordaba algunos estudios sobre el uso de este juego como elemento constitutivo del acompañamiento comunitario en los velorios y novenas de las comunidades negras del Atrato (Arocha et al. 2008).

Mi observación del juego fue interrumpida por Leyner. Con un ademán me pidió que me acercara a él y a un hombre joven que le decía: "yo nunca había estado en la iglesia de nuevo [...] mi mujer estaba embarazada cuando murió”. El

Esta práctica ritual requiere mayor exploración y análisis respecto a su ejecución en la región del Medio Atrato. Arocha et al. (2008, 56-104) brindan indicios acerca del tema, al hacer un amplio registro etnográfico sobre esta práctica y vincularla como elemento de la iconografía de los ritos fúnebres de las comunidades negras, afrocolombianas, raizales y palenqueras, adscritos a la novena y especialmente a su última noche. 
joven, quien perdió a su esposa y cinco hijos, hasta entonces, nunca había participado en la conmemoración de la masacre y ese día se animó a permanecer fuera de la iglesia mientras en el interior se escuchaba el alabao: "camina la virgen pura / en busca de su hijo amado / y en busca de su hijo amado / y en busca de su hijo amado / en busca de su hijo amado" (notas de campo, mayo del 2014).

2. En el 2012, al cumplirse diez años de la masacre, algo que nunca se había realizado en los aniversarios/conmemoraciones anteriores se presentó en la cancha de fútbol del nuevo pueblo de Bellavista. En medio del acto cultural realizado la noche del 1. ${ }^{\circ}$ de mayo, el joven presentador dijo: "ahora, un gualí por nuestros niños muertos”. Paso seguido, un grupo de aproximadamente veinte mujeres hablaban entre ellas y otro grupo de tres organizaba unas prendas blancas que envolvieron y empezaron a mecer. Cuando el canto comenzó, lo hicieron al compás de gestos y movimientos que tenían que ver con el envoltorio de trapos blancos. Al tiempo que los bamboleaban de un lado a otro, se fue creando un ambiente juguetón entre todos los que estábamos sentados en las gradas. Delegados de consejos comunitarios y de comunidades indígenas, niños, mujeres y hombres sonreían dejándose contagiar por el clima que el canto, el movimiento y los gestos de estas mujeres iban irradiando. Yo, también alegre, apenas podía comprender algunas frases o palabras de esos cantos. "Manatí", "Que te vas, que te vas” y “cógete los cojones” fueron las notas que registré al día siguiente. Recuerdo mucho a la mujer de más edad, quien bajita, trenzada y con un rostro profundamente encantador resaltaba en gestualidad y movimiento con respecto a las demás. Ella insistía en tener el envoltorio, acunarlo y lanzarlo por los aires para que las más jóvenes lo atraparan sin dejarlo caer. Todas disfrutaban y nos hacían disfrutar el gualí, un ritual jugado que por primera vez se realizaba por los niños muertos en la masacre.

Para Losonczy (2006), el aniversario de muerte hace parte tanto de la faceta individual como colectiva del ciclo ritual con los muertos. En lo que respecta a la faceta colectiva, la autora precisa que el aniversario se encuentra adscrito a tres momentos sujetos "al ritmo del calendario católico: la Semana Santa, el periodo de Navidad y la fiesta del santo patrón” (171). Además, al referirse a los rituales colectivos cíclicos de las comunidades negras, la autora señala que el periodo que unifica buena parte del campo ritual, incluidos los ritos funerarios, es el de nueve días y nueve noches (177).

A partir de estas referencias podríamos decir que el acompañamiento ritual colectivo a difuntos, dolientes y deudos tiene origen y énfasis participativo en el velorio, posteriormente en el novenario y luego en los momentos de recordación de la muerte. Así, tendríamos que el periodo que comprende el campo 
ritual de acompañamiento colectivo del muerto es, para los que mueren siendo adultos, de nueve días y nueve noches, y después, de un mes y un año. Por otra parte, para quienes mueren siendo niños, el ritual del gualí comprende la noche de velorio, el día del entierro y el aniversario ${ }^{35}$.

La profesora Ayala (2011) señala que la trascendencia de los aniversarios o cabo de año en la experiencia mortuoria de las poblaciones afroatrateñas es reciente, pues recuerda y registra en sus notas que el acto de recordación se anclaba en la realización de una misa que, una vez culminada, no tenía prolongación del encuentro entre dolientes y acompañantes. Sin embargo, afirma que en la actualidad el aniversario, además de ser un espacio eucarístico de recordación del muerto, es un espacio de integración en el que se comparten los gastos por el pago de la misa, se participa en el arreglo de la iglesia y en la elaboración de llaveros, medallas y fotografías del difunto, y puede ampliarse hacia la posibilidad de encuentro en una casa de familia una noche antes y la noche del aniversario ${ }^{36}$ (Ayala 2011, 105-106).

Se puede decir, entonces, que los ritmos temporales adscritos a la buena muerte y que caracterizan el ciclo de despedida de los muertos no es el ejecutado en la ritualidad orientada a tratar las secuelas familiares y comunitarias ocasionadas por el crimen del 2002. La realización ininterrumpida de aniversarios y conmemoraciones de la mala (y masiva) muerte que ocasionó la masacre de Bojayá ha establecido un ciclo colectivo de acompañamiento ritual que ha rebasado los marcadores temporales prescritos. No dejar de hacer cada año el aniversarioconmemoración de la masacre se ha convertido en el nuevo precepto a cumplir.

Este nuevo estatuto temporal para la recordación de los muertos de la masacre de Bojayá entra en diálogo con el estatuto temporal de las fiestas patronales ${ }^{37}$ que se ejecutan en cada una de las comunidades del Atrato. Como se

35 Los momentos de recordación de la muerte del ser querido pueden expandirse aún más de acuerdo con la gestión que de estos realicen los parientes más cercanos. Así, pueden ampliarse al segundo, tercer, cuarto o quinto año del fallecimiento, o restringirse a menos de los nueve días por la "burocratización de los ritos fúnebres" (Arocha et al. 2008) que realizan las funerarias.

36 Tobón (2016) también refiere el aniversario, pero vinculado a la palabra conmemoración: "La otra ceremonia fúnebre que celebran los atrateños corresponde al encuentro colectivo para conmemorar el aniversario de la muerte de un miembro adulto de la comunidad. Es frecuente que se celebre el primero y cuarto año. Zoraida Pino detalla que 'se canta en el cabo de año para que el ser querido escuche desde allá el susurro de nosotros, lo único que él puede escuchar es el alabao... el último día de la novena el difunto sale de la casa y no vuelve más, pero al año se le reza y se le recuerda para que no nos olvide... al cuarto año ya no queda ni la ceniza en el cementerio, es la última vez que se pide por su alma'” (146).

37 Para ampliar el análisis sobre las fiestas patronales en el Atrato, véanse Ayala (2010), Córdoba (2009) y Quiceno (2015). Para un análisis de las fiestas patronales como huella de africanía, véase Arocha et al. (2008). 
mencionó, la faceta colectiva del ritual de acompañamiento al muerto se vincula, entre otros momentos, a la fiesta del santo patrón establecida por el calendario católico. En dicho calendario, la fiesta de la Virgen del Carmen, patrona de Bojayá, está fechada el 16 de julio, pero su duración para los bellavisteños y atrateños comprende varios días antes y varios días después de dicho marcador temporal.

En consonancia con lo anterior, recordar a los muertos de la masacre de Bojayá ha implicado en los aniversarios/conmemoraciones más recientes la expansión paulatina del marcador temporal del 2 de mayo que en los primeros años de conmemoración de la masacre fue agenciada por la Diócesis de Quibdó en torno a la misa y eucaristía católica. Si retomamos el primer gualí realizado en el 2012 por los niños muertos de la toma del 2002, se encuentra que la práctica ritual se realizó diez años después de la masacre y un 1. ${ }^{\circ}$ de mayo, es decir, un día antes de la fecha que configura el marcador temporal de la conmemoración de la masacre en lo que podríamos llamar el calendario transicional colombiano ${ }^{38}$. Así, el calendario transicional y el calendario católico son expandidos por las relaciones que la muerte masiva y violenta ha propiciado entre familiares y difuntos, las cuales se materializan en prácticas rituales que, como señala Quiceno (2015), se configuran más bien por principios como el encuentro, la compañía y la solidaridad. Dolientes y líderes han procurado, por tanto, que la recordación de sus muertos y su presencia en la vida de las comunidades del Medio Atrato den cuenta de una temporalidad ritual que garantice los ritmos locales que son necesarios para el encuentro colectivo atrateño.

Dichos ritmos locales revelan además la expansión de espacios para la realización de las prácticas rituales mortuorias. Así, tenemos que la ejecución del ritual de cuerpo presente se lleva a cabo en la iglesia donde años atrás solo se celebraba la eucaristía católica y la del gualí, en la cancha del pueblo nuevo de Bellavista, un espacio de encuentro comunitario cuya materialidad está orientada al esparcimiento, el juego y el deporte. Además, aparece el ritmo temporal de la noche para la ejecución de estas dos prácticas rituales en una clara semblanza de la temporalidad en la que se ejecutan los velorios y las novenas; un ritmo que logra convocar la participación de personas que durante muchos años no se sienten en la capacidad de entrar a la iglesia donde aconteció la mala muerte de sus seres queridos, pero que les ofrece tiempos y espacios más acordes con sus maneras más íntimas y privadas de tratar su dolor.

38 Llamo calendario transicional colombiano al dispositivo temporal y moral de recordación de fechas que se ha configurado a la par de los escenarios transicionales de reparación, verdad y justicia. La fecha emblemática de dicho calendario es el 9 de abril, instituido por la Ley 1448 del 2011 como el Día Nacional de la Memoria y la Solidaridad con las Víctimas del Conflicto Armado. 
En síntesis, si comparamos los primeros aniversarios/conmemoraciones (2003-2007) con los más recientes (2012-2018), encontramos que los primeros fueron liderados por la Diócesis de Quibdó ${ }^{39}$ a través de la eucaristía católica del 2 de mayo en horas de la mañana. En los más recientes, las prácticas rituales ya no son ejecutadas exclusivamente por los representantes locales de la Iglesia católica, sino que comienzan a ser agenciadas por líderes locales - la mayoría sobrevivientes de la masacre- que basan sus decisiones en el saber de cantadoras, rezanderos y, más recientemente, en médicos tradicionales de las comunidades indígenas embera dovida ${ }^{40}$. Dicha agencia hace que se renueven y reinventen prácticas mortuorias prescritas como la del gualí o la del ritual de cuerpo presente. Aquí, la frontera temporal y espacial establecida por el calendario católico y el calendario transicional de nuevo se amplía para el despliegue innovador, flexible y dinámico de las prácticas rituales afroatrateñas.

Finalmente, otro elemento podría estar en la base de la expansión temporal del aniversario por la mala muerte masiva y violenta de la masacre. Para Millán (2009), la muerte producida por el crimen del 2002 aconteció en la iglesia y en la mañana, es decir, en el espacio-tiempo de lo habitado ${ }^{41}$. Sin embargo, esta reflexión refiere solo la muerte acontecida durante la mañana del 2 de mayo del 2002 en la iglesia San Pablo Apóstol de Bellavista, excluyendo la experiencia de las muertes que acontecieron entre abril y mayo del 2002 en Napipí, Puerto Conto y Vigía del Fuerte, además de las de aquellas personas afectadas física y emocionalmente por las esquirlas de los explosivos.

"Un gualí por nuestros niños muertos” y "Un ritual de cuerpo presente" fueron prácticas rituales que aprecié de forma especial en los aniversarios/conmemoración. Dan cuenta de la transformación e innovación de las prescripciones rituales tradicionales, a la vez que mantienen un nodo para su realización que se moldea y modula de acuerdo con el conocimiento de rezanderos, cantadoras o conocedores y trabajadores de la muerte, que se abre paso con el transcurrir de los años. En las primeras conmemoraciones/aniversarios de la masacre, el nodo de relación colectiva con los muertos fue la misa orientada por la Iglesia católica.

39 Para revisar estudios referidos al papel de la Diócesis de Quibdó en los procesos de memoria y relación con los muertos de la masacre, véase Ríos (2015).

40 El estudio de la relación entre prácticas mortuorias indígenas y prácticas mortuorias afros en el Atrato podría dar cuenta de un elemento adicional que se debe tener en cuenta para la comprensión del entretejido ritual flexible, dinámico y cambiante que ha agenciado la mala (y masiva) muerte.

41 Para la autora, la iglesia y la mañana en que ocurrió la muerte de más de ochenta personas pertenecen al espacio-tiempo de lo habitado, lo cual modifica la concepción de que la mala muerte acontece en el lugar de la selva, de lo bajo, del inframundo (Millán 2009). 
En algún momento, al desarrollo de la eucaristía se le suma la participación de las cantadoras de alabao y más tarde este grupo de mujeres, acompañado de líderes locales, propone los espacios y los tiempos de las prácticas rituales que son acordes con el tipo de muertes ocurridas entre abril y mayo del 2002. Podemos observar que lo que se hace, el lugar donde se hace y el tiempo en que se hace configuran un entretejido ritual, sustentado en una multiplicidad de relaciones emergentes que consolidan respuestas renovadas y diversificadas del vínculo con los muertos.

Lo anterior quiere decir que el aniversario/conmemoración: 1) se gesta como práctica ritual más allá del 2 de mayo e incluye ritmos temporales que contemplan el día y la noche para su realización; 2) ha requerido, para llevarse a cabo, espacios como el cementerio, el río, el hoyo al que en primer lugar fueron trasladados los cuerpos de los muertos, la cancha del polideportivo, entre otros, y no solo la parroquia San Pablo Apóstol del pueblo viejo de Bellavista; 3) ha posicionado la agencia de saberes expertos locales para asegurar la relación entre la vida y la muerte; 4) vincula progresivamente, con el paso de los años, las experiencias de acompañamiento ritual que son constitutivas de las prácticas mortuorias; y 5) recuerda, enuncia y reconoce a los muertos del 2 de mayo a la vez que a los muertos de hechos anteriores y posteriores a la explosión de la pipeta en la iglesia ${ }^{42}$.

\footnotetext{
42 Podría pensarse que en un futuro no lejano los ritmos temporales locales deriven en experiencias que vinculen el aniversario con la fiesta de un nuevo posible santo patrón: el Cristo Mutilado de Bojayá.
} 
Figura 2. Oración en el hoyo en el cual los cuerpos de los muertos estuvieron hasta la exhumación realizada por la Fiscalía y Medicina Legal en el 2002

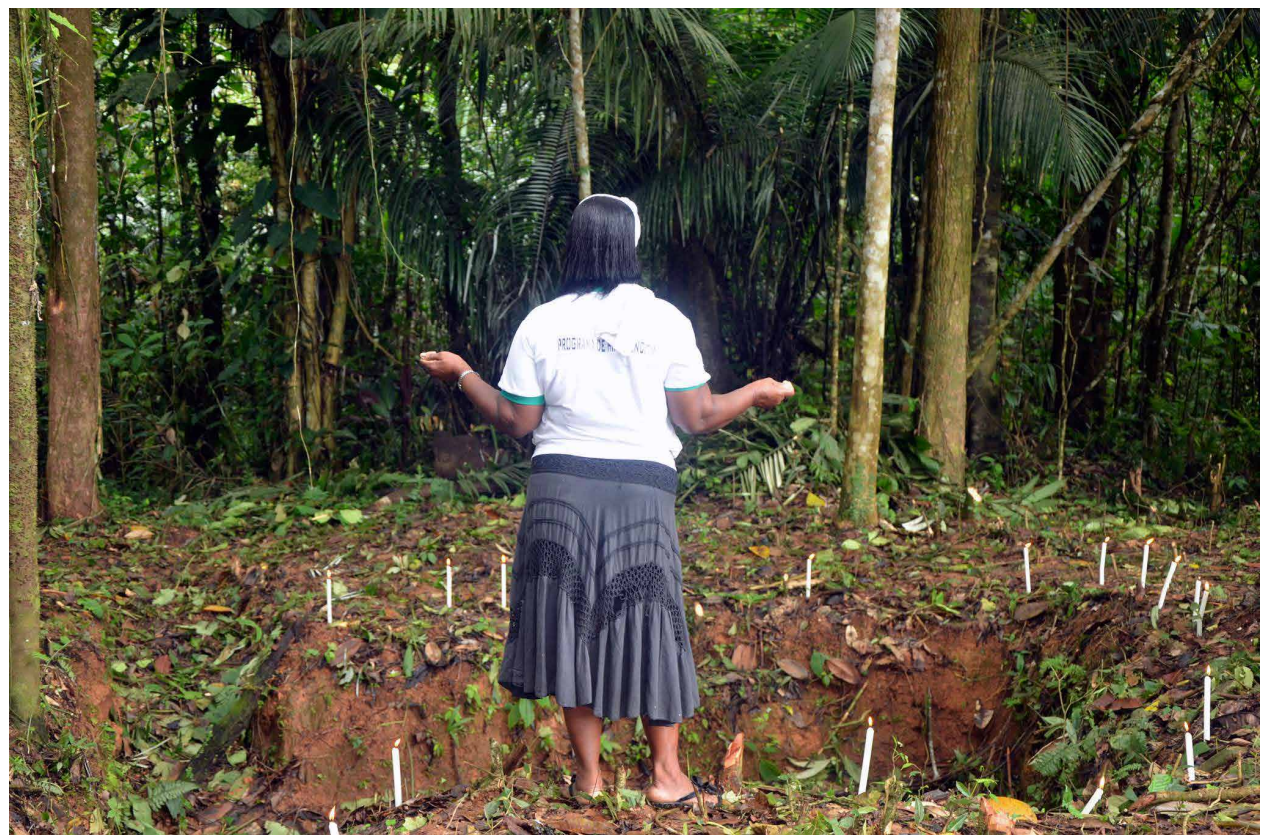

Fuente: fotografía de Camila Orjuela Villanueva, 2 de mayo del 2015.

\section{¿Dónde estaban las demás víctimas?: enterradas como perros}

Entre recoger los cuerpos de los muertos para llevarlos a un hoyo provisional y la transformación e innovación de las prácticas rituales que han mantenido la relación entre vivos y muertos, también se han configurado múltiples relaciones originadas en la diversidad de paisas - personas no afros externas a la comunidad-que han llegado al Medio Atrato, con perspectivas y dimensiones de la vida y la muerte que en muchas ocasiones entran en contradicción con las de las comunidades locales.

En la exhumación e inhumación realizada por la Fiscalía y Medicina Legal en el 2002, la experiencia de enterramiento transitorio de los muertos llevada a cabo por Domingo y otros hombres de la comunidad derivó en una situación en la que muchos muertos quedaron perdidos y sin nombre. Visitar el cementerio 
en las primeras conmemoraciones era experimentar un paisaje de cruces de madera, marcadas con números (actas de defunción) y, en algunos casos, telas en las que se escribió con pintura el nombre de la víctima mortal. Con el pasar de los años, tanto cruces como telas fueron paulatinamente reemplazadas por las palmas de cristo.

Figura 3. Cementerio de Bellavista. El Fuerte

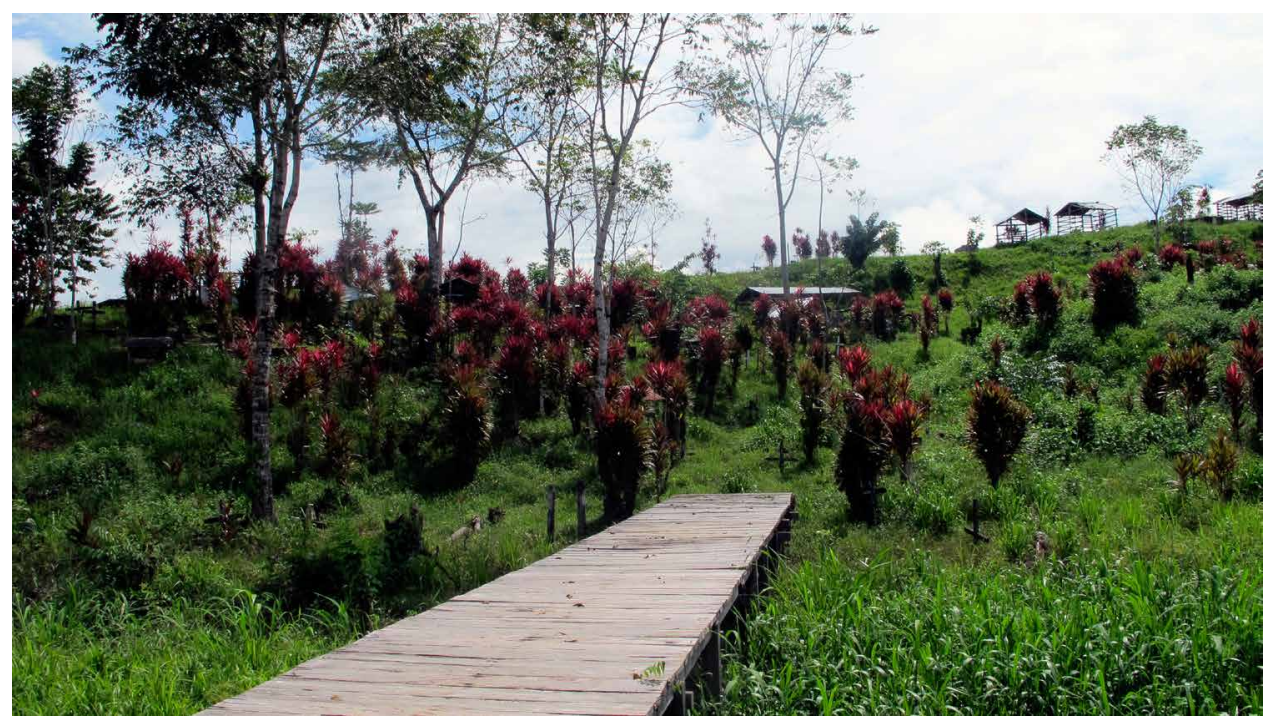

Fuente: fotografía de Camila Orjuela Villanueva, 7 de diciembre del 2013.

La primera vez que estuve en el cementerio de Bellavista, solo unas pocas lápidas registraban el 2 de mayo del 2002 como fecha de muerte. ¿Dónde estaban las demás víctimas?: “enterradas como perros”, decía la gente, en bolsas y sin cajón. "Ya los palos se cayeron / la bandera se pudrió", cantaba Domingo, quien años atrás los recogió y dispuso en un hoyo a orillas del río Bojayá.

Con la realización de un segundo proceso forense para recuperar los cuerpos de las víctimas mortales del 2002 en el Medio Atrato - en el marco de la implementación de los acuerdos de paz-, el 8 de mayo del 2017 se llevó a cabo la diligencia para exhumar el cuerpo de Ubertina Martínez en el cementerio de Vigía del Fuerte. Recuperar el cuerpo de Ubertina fue especialmente difícil. Con la ayuda de su padre, los expertos cavaron varias capas de tierra sin tener resultado. El antropólogo forense encargado insistía en encontrarla. Cada lugar referido por el padre era cuidadosamente revisado, se cavaba aquí, se cavaba allá, pero Ubertina no quería aparecer. Cada hoyo abierto sofocaba tanto como la mezcla de lluvia, humedad, calor y zancudos. Ubertina fue encontrada en horas de la tarde y el procedimiento de exhumación duró casi cuatro horas. Al culminar 
la exhumación, el cuerpo fue recuperado, embalado y rotulado, los profesionales forenses, los familiares, líderes, rezanderos y cantadoras empezaron a recoger las sillas, los termos y las sombrillas. Cuando todos estábamos listos para emprender el viaje hacia los botes que nos trasladarían a Bellavista y Vigía del Fuerte, el fiscal encargado del caso nos dijo: "Es una falta de respeto con la familia de Ubertina que hayan estado riéndose y burlándose mientras se hacía la diligencia”. Entre el cansancio que había dejado la jornada y el desconcierto que habían producido las palabras del fiscal, nadie atinó a decir nada. La acusación de irrespeto se basó en su percepción del encuentro espontáneo que produjo la dura jornada entre quienes estábamos presentes. El espacio físico, espontáneamente creado, nos resguardó de la lluvia mientras chistes y cuentos eran contados a todo pulmón especialmente por Boris, un joven teatrero de Bellavista, el padre de Ubertina y un viejo rezandero, conocido en casi toda la cuenca media del Atrato como Belén, que viajó desde el Consejo Comunitario de La Boba. Sin ser versada en el arte de contar chistes o cuentos, yo escuchaba palabras y frases, pero muy pocas veces entendía el sentido o los desenlaces propuestos por ellos. Observé al padre de Ubertina yendo y volviendo varias veces entre el hoyo y el espacio del chiste, el cuento y la bulla. Con una pala en su mano, iba y venía entre la nostalgia y el humor.

Un día, cuando tomaba un café en Bogotá con Noel Palacios, quien vivió la masacre y se radicó en Bogotá para componer y producir su propia música, me habló de la molestia que tenía porque la muerte en Bojayá se había vuelto un negocio: "es que cuando alguien muere, usted se queda toda la noche con el muerto, se juega rummy, dominó, se le acompaña haciendo bulla, eso sí, cuando hay que rezar, todo eso se para" (notas de campo, 2013). Boris, el joven teatrero de Bellavista, me relató días después que los chistes eran "cien por cien cultura y costumbre", y que se usaban en velorios y entierros, dirigidos especialmente al doliente más cercano del muerto, "pa sacarlos del confort... de la nostalgia en la que se encuentran”. Por su parte, las historias contadas por don Belén eran "cuentos cortos de la historia real que es larguísima", muchas veces difíciles de entender y seguir en su gracia para quienes no somos atrateños. Así, lo que había sido concebido como el tiempo de cuidado y acompañamiento para dolientes, colmado de risas y carcajadas, para el fiscal había sido una acción que iba en contravía de sus propias formas de concebir el respeto hacia la muerte, los muertos y especialmente con las diligencias que estaban a su cargo.

Desde otra perspectiva que contrasta con la del funcionario de la Fiscalía, el padre Esterling Londoño, coordinador de la pastoral afro de la Diócesis de Quibdó, dijo a los participantes de una de las misas que se hizo al terminar una de las jornadas de exhumación: 
Yo no sé si las hermanas [misioneras agustinas] estén de acuerdo con lo que voy a decir, pero voy a decir algo. Esta noche los que quieran que nos reunamos un ratico, nos reunimos un ratico, los que quieran. Pero el que vaya debe llevar por lo menos un verso, por lo menos un chiste, por lo menos una poesía, para que compartamos un ratico... el que quiera ir, no es obligatorio. Si llueve... ¡Saulo!, usted y yo rezamos alguna cosa para que ese aguacero se vaya para algún lado. (Notas de campo, mayo del 2017)

El chiste, el relato de historias, el juego del rummy, el dominó e incluso la bulla en modos controlados de expresión son todos elementos constitutivos de las prácticas rituales orientadas a los muertos y a permanecer en la compañía colectiva para afrontar el dolor de las ausencias. Frente a las difíciles condiciones que presenta la mala (y masiva) muerte ocasionada por la violencia y el conflicto armado, aparecen el diálogo, la concertación o tensión entre prácticas mortuorias diversas que se corresponden con nociones y perspectivas, en ocasiones distintas, sobre la muerte, la vida y la relación entre muertos y vivos de Bojayá.

No obstante, es importante señalar que las acciones que relacionan a los muertos de la masacre de Bojayá con actores externos a la comunidad y a las familias afectadas obran de modo paradójico. El dinamismo, la transformación y el ritmo temporal de estas prácticas evidencia, por un lado, el accionar infringido por la llamada política de cadáveres o de las disciplinas de los muertos ${ }^{43}$ (Rousseau 2015), y por otro, el encuentro y la solidaridad que propician los familiares y la comunidad con respecto al tratamiento local de la muerte masiva, violenta y abrupta. Una y otra perspectiva agencian renovadas prácticas mortuorias que vinculan formas, modos, tiempos, espacios y roles en permanente diversificación.

Otro ejemplo. Con ocasión de la undécima conmemoración/aniversario, se inauguró una escultura en homenaje a los muertos en lo que hasta ese entonces se llamaba la plaza central del pueblo. En horas de la mañana, cuando un grupo de jóvenes cavaba el hueco para su instalación, me acerqué con unos colegas e indagamos por el origen de la iniciativa. Herling, representante de una de las organizaciones de víctimas de Bellavista y participante activo de las obras de teatro presentadas cada 2 de mayo, nos contó que el Libro de mármol, una escultura con el nombre de las víctimas mortales, había sido propuesto por la alcaldía. Indagué por la participación de las víctimas o la comunidad en el proceso y me contestó que el libro había sido encargado sin necesidad de consulta alguna. Mientras

43 Estas nociones remiten a la relación entre el campo de las ciencias forenses constituidas especialmente por disciplinas como la antropología, la arqueología y la medicina genética, y al campo que concibe la potencia de los cadáveres para articular las políticas que surgen entre individuos, disciplinas e instituciones para reaccionar de ciertas maneras, invocando prácticas o rituales particulares (Rousseau 2015, 176). 
el sudor bajaba por el rostro de los jóvenes a cargo de la tarea de instalación, llegó un hombre paisa con los botones de la camisa desapuntados que dejaban ver una cadena de la que colgaba una cruz de tamaño muy generoso sobre su pecho. Herling se apresuró a presentárnoslo: “él es el de la idea del libro”. Tras una presentación formal, nos contó el sentido de su obra: "aquí la gente se olvidó de sus muertos, y yo quería brindarle algo al pueblo, para que la memoria de lo que ocurrió, no se olvide [...]. Un día le dije al alcalde de la idea y así fue que fue posible" (notas de campo, mayo del 2013).

\section{Figura 4. Libro del presente o Libro de mármol}

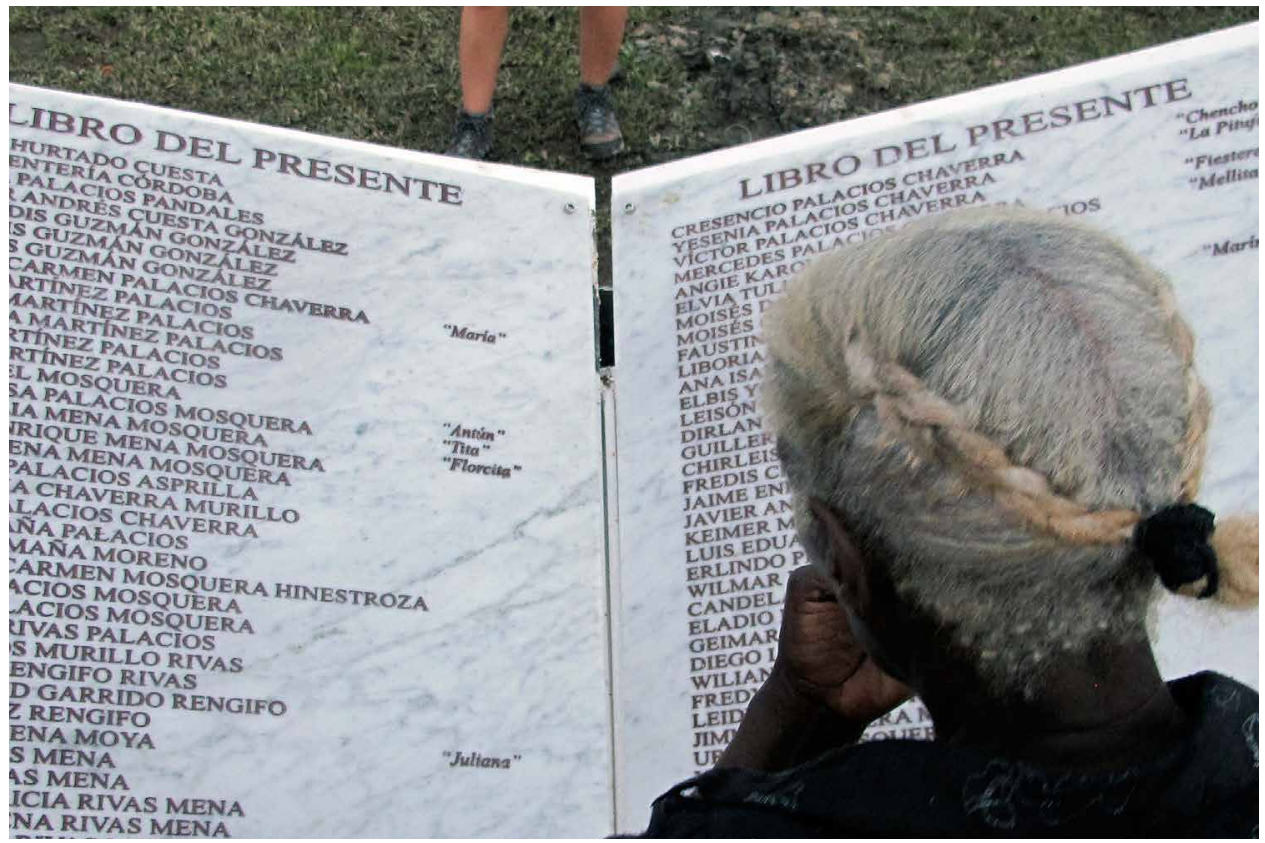

Fuente: fotografía de Camila Orjuela Villanueva, 2 de mayo del 2013.

Era mediodía y el sol a esa hora era abrasador, así que unos minutos más tarde me trasladé a una tienda que estaba justo al frente del lugar. Domingo, el compositor, cantante y sepulturero, llegó a la tienda, se sentó junto a mí y me dijo: "Ay, home, ese libro era pa que estuviera en el cementerio. ¿No cree usted, Camila? Yo le dije al alcalde”. Le pregunté: “¿y por qué en el cementerio, Domingo?”; y me respondió: “pa que tengan su señal, porque allá no se sabe dónde están”. Tras otros minutos, llegó un hombre de contextura alta y robusta, saludó a Domingo y también se sentó. Luego supe por Domingo que era el profesor de artes del colegio de Bellavista. En tríada observamos el trabajo de los muchachos, quienes en ese punto ya conformaban un grupo más grande y trataban de sujetar la 
segunda pieza de la obra-monumento: "una bandera blanca que no ondea para ningún lado. La bandera debía moverse, así poco sentido tiene”, nos comentó el profe. Domingo y yo, sin pronunciar palabra, asentimos con la cabeza ${ }^{44}$ (notas de campo, mayo del 2013).

Figura 5. Libro del presente o Libro de mármol y bandera de la paz

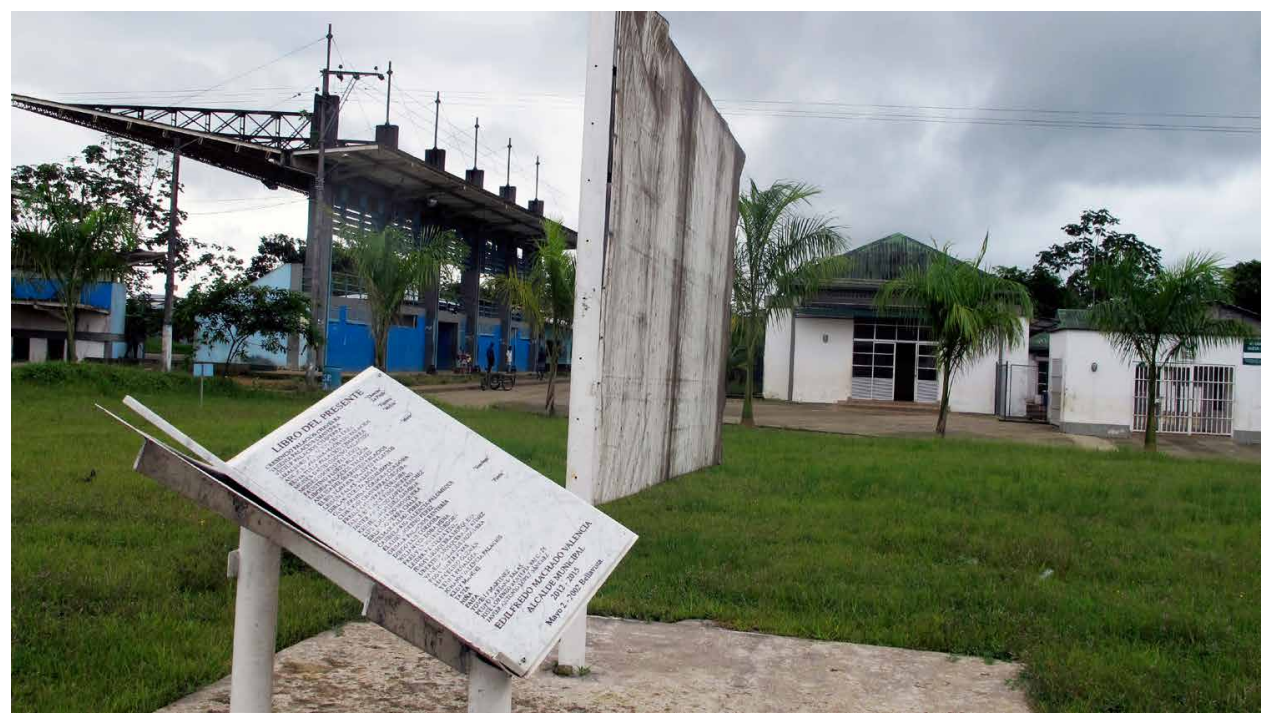

Fuente: fotografía de Camila Orjuela Villanueva, 2 de mayo del 2013.

A partir de lo señalado, podría decir que el conjunto de prácticas de relación con los muertos de la masacre de Bojayá obedece al carácter flexible, plástico e innovador que caracteriza el campo ritual de las comunidades negras. A su vez, los actores y estructuras instituidas para hacer justicia, saber la verdad y reparar a las víctimas del conflicto armado colombiano se han entretejido paulatinamente con las prácticas mortuorias que emergieron tras el crimen, las cuales además fueron y siguen siendo dinamizadas por los procedimientos forenses, la histórica relación de las comunidades con la Iglesia católica y el reciente vínculo con grupos religiosos evangélicos. En resumen, con la convergencia de múltiples actores, entidades, instituciones y organizaciones no atrateñas que difieren en sus intereses y en las relaciones de poder con los vivos y los muertos de Bojayá.

44 En julio del 2016, en cumplimiento de la Sentencia 79 del 31 de octubre del 2016, el Ministerio del Interior y el Ejército Nacional entregaron un parque como medida de reparación y homenaje por los niños y niñas muertos en la masacre. La obra se hizo en la plaza central y obligó al retiro del Libro del presente y de la bandera. Cuando pregunté por el destino de los artefactos retirados, la mayoría de gente no me dio razón; otros dijeron que estaban en el basurero local. 


\section{En espera de un cierre}

Colombia es un país devastado por la muerte violenta: su magnitud, persistencia y permanencia la convierten, como señala Diéguez (2013), en "un límite real, una dimensión matérica, un olor” (29), que inevitablemente y de algún modo nos alcanza a todos. Tras el crimen conocido como la masacre de Bojayá, se ha desarrollado un conjunto de prácticas rituales que buscan darles descanso a los muertos que produjo el combate entre la guerrilla y los paramilitares entre abril y mayo del 2002. La mala (y masiva) muerte ha puesto en tensión las prácticas mortuorias que han eclosionado entre el año del crimen y la actualidad. Dichas prácticas han supuesto el agenciamiento de roles comunitarios expertos en el manejo de los muertos que no tienen un "buen morir" (Velásquez [1961] 2000), para que ellos adquieran su estatuto e identidad en la vida de los vivos como ancestros y ángeles protectores. Han supuesto, además, la plasticidad y ampliación de las fronteras de sus prácticas rituales tradicionales, procurando la protección, resguardo y agencia de la espiritualidad antigua ${ }^{45}$ ante la intervención de múltiples actores e intereses externos.

Por otra parte, el sostenimiento de un ciclo ritual y colectivo con los muertos ha puesto de presente la innovación, creatividad, cambio y espontaneidad de los trabajos orientados a los muertos. Si bien las prescripciones rituales mortuorias se han transformado (cantar alabaos en actos públicos distintos a velorios, novenas y entierros; hacer un gualí en el polideportivo del pueblo; enterrar en lugares de disposición transitoria, entre otras), las prácticas y quienes las agencian mantienen un nodo para su realización que se expresa, moldea o transforma con respecto a los modos tradicionales de concebir la muerte y la vida en el Medio Atrato. Existe, además, otro conjunto de vínculos que desborda el campo ritual tradicional orientado a rezar, cantar, acompañar, velar y despedir a los muertos. Nuevos actores, con intereses diversos y concepciones sobre la vida y la muerte distintas a las de las comunidades del Medio Atrato, pero adscritos a las múltiples perspectivas y moralidades forjadas por los “escenarios transicionales”, dinamizan también el entramado de lazos que mantienen presentes a los muertos en la experiencia cotidiana de los vivos. El conjunto de prácticas múltiples y diversificadas para relacionarse con los muertos ha configurado un entretejido que

45 Noción empleada por Saulo Mosquera, rezandero y cantador, con el objetivo de posicionar el saber espiritual particular de las comunidades afros e indígenas que participaron con sus saberes ancestrales sobre la vida, la muerte y el tratamiento de los muertos en los procesos y procedimientos forenses que fueron orientados a la exhumación, individualización, identificación y entierro de los difuntos de la toma. 
implica una dimensión ritual, pero también la excede con el objetivo de saldar la deuda mantenida por más de dieciocho años entre los sobrevivientes y los muertos que dejó la masacre de Bojayá.

Este artículo está dedicado a la entereza e ímpetu con que los líderes y las organizaciones del Medio Atrato despliegan la vida política propia y la de sus muertos. Su escritura es un agradecimiento a los aprendizajes que me han brindado con respecto a su inquebrantable relación entre vida y muerte. Es, además, un homenaje a los difuntos de mis últimos tiempos. Agradezco la orientación y acompañamiento del profesor Pablo Jaramillo en las reflexiones que sustentaron las primeras versiones de este artículo.

\section{Referencias}

Almario, Oscar. 2001. "Tras las huellas de los renacientes. Por el laberinto de la etnicidad e identidad de los grupos negros o ‘afrocolombianos' del Pacífico sur”. En Acción colectiva, Estado y etnicidad en el Pacífico colombiano, editado por Mauricio Pardo, 15-40. Bogotá: Instituto Colombiano de Antropología e Historia; Colciencias.

Arocha, Jaime, Juliana Botero, Alejandro Camargo, Sofía González, Cristina Lleras, Dilia Robinson, Alfonso Cassiani, Carlos Andrés Meza, Óscar Almario, Mario Diego Romero, Zamira Díaz, Ramiro Delgado y Lina del Mar Moreno. 2008. Velorios y santos vivos, comunidades negras, afrocolombianas, raizales y palenqueras. Bogotá: Museo Nacional de Colombia.

Ayala, Ana Gilma. 2010. Amuletos y santos en el Atrato. Serie Mis Ancestros. Medellín: Mundo Libro.

-. 2011. Rituales mortuorios afroatrateños en el Alto y Medio Atrato. Serie Mis Ancestros. Medellín: Mundo Libro.

Castillejo, Alejandro. 2015. "La imaginación social del porvenir: reflexiones sobre Colombia y el prospecto de una Comisión de la Verdad”. Consultado el 23 de agosto del 2019. http://biblioteca.clacso.edu.ar/clacso/becas/20150131091650/CastillejoFinal.pdf

Castro Ramírez, Luis Carlos. 2015. “Caballos, jinetes y monturas ancestrales: configuración de identidades diaspóricas en las prácticas religiosas afro en Colombia”. Tesis doctoral, Departamento de Antropología, Universidad de los Andes, Bogotá.

Córdoba, José. 2009. "Resistencia festiva: Fiesta de San Antonio de Padua en Tanguí, Chocó, en el contexto del conflicto armado (1996-2008)”. Tesis de maestría, Departamento de Antropología, Universidad de los Andes, Bogotá. 
Diéguez Caballero, Ileana. 2013. Cuerpos sin duelo: iconografías y teatralidades del dolor. Monterrey, Nuevo León: Universidad Autónoma de Nuevo León.

Escobar, Arturo. 2015. "Territorios de diferencia: la ontología política de los derechos al territorio”. Desenvolvimento e Meio Ambiente 35: 25-38. DOI: 10.5380/dma.v35i0.43541

GMH-CNRR (Grupo de Memoria Histórica-Comisión Nacional de Reparación y Reconciliación). 2010. Bojayá. La guerra sin límites. Bogotá: Taurus.

Goldman, Marcio. 2016. "Cosmopolíticas, etnoontologías y otras epistemologías. La antropología como teoría etnográfica”. Cuadernos de Antropología Social 44: 27-35. https://doi. org/10.34096/cas.i44.3578

Gómez Nadal, Paco. 2012. Los muertos no hablan. Edición Bojayá, una década (2002-2012). Medellín: Otramérica.

Losonczy, Anne Marie. 2006. La trama interétnica: ritual, sociedad y figuras del intercambio entre los grupos negros y embera del Chocó. Bogotá: Instituto Colombiano de Antropología e Historia.

Millán, Constanza. 2009. "Ya no llega el limbo porque la gente bailando está. Prácticas de memoria en Bojayá-Chocó”. Tesis de maestría, Departamento de Antropología, Universidad Nacional de Colombia, Bogotá.

Ministerio de Cultura, Fundación Cultural de Andagoya. 2014. "Plan Especial de Salvaguardia de la Manifestación, Gualíes, Alabaos y Levantamientos de Tumba, Ritos Mortuorios de las Comunidades Afro del Municipio del Medio San Juan”. Consultado el 21 de febrero del 2020. http://patrimonio.mincultura.gov.co/SiteAssets/Paginas/ Gual\%C3\%ADes,-alabaos-y-levantamientos-de-tumba,-ritos-mortuorios-de-las-comunidades-afro-del-Medio-San-Juan/17-Gual\%C3\%ADes,\%20alabaos\%20y\%20levantamientos\%20de\%20tumba,\%20ritos\%20mortuorios\%20de\%20las\%20comunidades\%20afro\%20 del\%20Medio\%20San\%20Juan\%20-\%20PES.pdf

Mosquera, Saulo y Camila Orjuela. 2017. "Espiritualidades atrateñas. Fuerzas vitales para tramitar la 'mala muerte'”. Ponencia presentada en el Coloquio Internacional de las Fosas Clandestinas a la Tumba Vacía: Narrativas de Dignidad y Esperanza en Tiempos de Horror, Universidad Iberoamericana, Ciudad de México, 9-10 de octubre.

Pinilla, Andrea. 2017. "Alabaos y conflicto armado en el Chocó: noticias de supervivencia y reinvención”. Revista Encuentros 15 (3): 152-169. DOI: http://dx.doi.org/10.15665/ re.v15i3.1096

Quiceno, Natalia. 2015. "Vivir sabroso. Poéticas de las luchas y movimientos afroatrateños. Bojayá, Chocó”. Tesis de doctorado, Departamento de Antropología Social, Universidad Federal de Rio de Janeiro, Río de Janeiro.

Quiceno Toro, Natalia, María Ochoa Sierra y Adriana Marcela Villamizar. 2017. "La política del canto y el poder de las alabaoras de Pogue (Bojayá, Chocó)”. Estudios Políticos 51: 175-195. DOI: 10.17533/udea.espo.n51a09

Restrepo, Eduardo. 2011. "Representaciones y prácticas asociadas a la muerte en los ríos Satinga y Sanquianga”. Piedra de Panduro (8): 78-102.

—. 2013. Estudios afrocolombianos hoy: aportes a un campo transdisciplinario. Popayán: Universidad del Cauca. 
Riaño, Pilar y Ricardo Chaparro. 2016. El oficio de cantar memoria. Las Musas de Pogue. Cartilla. Grupo de Cantadoras. Pogue, Bojayá. (Chocó-Colombia), Cocomacia, The University of British Columbia, Centro Nacional de Memoria Histórica.

Ríos, Sandra. 2015. Religion, Social Memory and Conflict. The Massacre of Bojayá in Colombia. The Netherlands: Utrecht University.

Rousseau, Nicky. 2015. "Identification, Politics, Disciplines: Missing Persons and Colonial Skeletons in South Africa”. Consultado el 3 de octubre del 2018. http://www.jstor.org/ stable/j.ctt1wn0s24.14

Serrano Amaya, J. 1998. “'Hemo de morí cantando, porque llorando nací. Ritos fúnebres como forma de cimarronaje”. En Los afrocolombianos. Geografía humana de Colombia, tomo VI, 181-200. Bogotá: Instituto Colombiano de Cultura Hispánica.

Tobón, Alejandro. 2016. Romances del Atrato, cantos de la vida y de la muerte. Bogotá: Instituto Caro y Cuervo.

Velásquez, Rogerio. (1961) 2000. “Ritos de la muerte en el Alto y Bajo Chocó (1961)”. En Fragmentos de historia, etnografía y narraciones del Pacífico colombiano negro, 127-172. Bogotá: Instituto Colombiano de Antropología e Historia.

Vergara Figueroa, Aurora. 2014. "Ripped from the Land, Shipped Away and Reborn: Unthinking the Conceptual and Socio-Geo-Historical Dimensions of the Massacre of Bellavista”. Tesis de maestría, Department of Sociology, University of Massachusetts, Amherst. 